\title{
Correction to: Cycle ergometer training enhances plasma interleukin-10 in multiple sclerosis
}

\author{
Alison Barry ${ }^{1} \cdot$ Owen Cronin $^{2}$ - Aisling M. Ryan ${ }^{3}$ • Brian Sweeney ${ }^{3}$ - Orna O'Toole ${ }^{4} \cdot$ Ken D. O'Halloran ${ }^{1}$. \\ Eric J. Downer ${ }^{5}$ (D)
}

Published online: 21 May 2019

(C) Fondazione Società Italiana di Neurologia 2019

\section{Correction to: Neurological Sciences 2019 \\ https://doi.org/10.1007/s10072-019-03915-2}

Following publication the authors informed the Journal that the published version of this article unfortunately contained a mistake. All occurrences of $\mathrm{pg} / \mu \mathrm{l}$ found in the original article should be changed to $\mathrm{pg} / \mathrm{L}$. The correction has no impact on the conclusions drawn in the manuscript. The original article has been corrected.

Pulisher's note Springer Nature remains neutral with regard to jurisdictional claims in published maps and institutional affiliations

The online version of the original article can be found at https://doi.org/ 10.1007/s10072-019-03915-2

Eric J. Downer

edowner@tcd.ie

1 Department of Physiology, School of Medicine, Western Gateway Building, University College Cork, Cork, Ireland

2 Department of Medicine, Cork University Hospital, Cork, Ireland

3 Department of Neurology, Cork University Hospital, Cork, Ireland

4 Mercy University Hospital, Cork, Ireland

5 Department of Physiology, School of Medicine, Trinity Biomedical Sciences Institute, Trinity College Dublin, University of Dublin,

Dublin 2, Ireland 